\title{
Evaluation of the frequency of the accompanying nasal symptoms in rhinoseptoplasty patients
}

\begin{abstract}
Background: The deviation of the nasal septum is one of the most frequent cause of nasal respiratory obstruction. Usually it appears parallel to a series of difficulties which additionally affect the patient's physical condition and disrupt their everyday activity and work. The patients with deviated nasal septum besides the chronic nasal obstruction as a dominant problem, state the following as the most frequent accompanying symptoms: rhinorrhea, nasal pain, headache, hyposmia, snoring, nasal speech and epistaxis.

Aim: Researches on the subjective measurements of the nasal symptoms has been limited. In our study we have monitored the patients for a period of one year. We monitored their nasal symptoms using tables and graphs and we tried to show in the simplest way what the benefit of the performed septorhinoplasty was and how it affected the reduction of their symptoms.

Matherial and methods: 140 patients-candidates for septorhinoplasty were admitted and operated at the University Clinic for Ear, Nose and Throat, University Campus "St. Mother Theresa" in Skopje in the period 2009-2016. Their nasal symptoms which appeared because of the deviation of nasal septum or possible changes in the nasal mucosa were observed. Before the operation, the nasal symptoms in all the patients-candidates for rhinoseptoplasty were observed: nasal obstruction, rhinorrhea, nasal pain, headache, hyposmia, snoring, nasal speech, epistaxis and other. They were recorded on the scale of nasal symptoms.

Conclusion: Our clinical research presented differences in the results obtained from the patients, that is, their interpretation of the nasal symptoms in relation to the results obtained from objective rhinomanometry measurements, as well as the anatomic abnormalities of the nasal septum obtained from the performed CT on the nose and the paranasal sinuses and the objective intraoperative findings. The results showed that besides the septal deviation, certain factors can cause reduced resistance in the nasal passages: nasal hypersecretion, nasal concha hyperplasia, isthmus stenosis, inspiratory nasal valve collapse or other factors that lead to pathological nasal turbulence. We must not forget the psychological factor at any time. Therefore, without appropriate postoperative nasal functional diagnostics, rhinoseptoplasty will not always be successful.
\end{abstract}

Keywords: rhinoseptoplasty, nasal obstruction, accompanying nasal symptoms, scaling and distribution of nasal symptoms
Volume 7 Issue 2 - 2017

\author{
Gabriela Kopacheva Barsova, Nikola \\ Nikolovski \\ University Clinic for Ear Nose and Throat Faculty of Medicine \\ Ss Cyril and Methodius University of Skopje, Macedonia
}

Correspondence: Gabriela Kopacheva Barsova University Clinic for Ear Nose and Throat Faculty of Medicine Ss Cyril and Methodius University of Skopje Vodnjanska 17 Skopje MK II 09 , Republic of Macedonia, Email gabrielak70@yahoo.com

Received: August 17, 2016 | Published: May 10, 2017

\section{Introduction}

The deviation of the nasal septum is one of the most frequent cause of nasal respiratory obstruction. Usually it appears parallel to a series of difficulties which additionally affect the patient's physical condition and disrupt their everyday activity and work. Therefore, as a logical consequence to the above mentioned, for a lot of patients who are candidates for functional or aesthetic-functional rhinoseptoplasty (RSP) we should ask the question whether there is a connection between the rate of nasal obstruction and the incidence and strength of the appearance of nasal symptoms which appear as a result of deviated nasal septum. The patients with deviated nasal septum besides the chronic nasal obstruction as a dominant problem, state the following as the most frequent accompanying symptoms: rhinorrhea, nasal pain, headache, hyposmia, snoring, nasal speech and epistaxis.

The deviation of the nasal septum has been reported as a significant factor in the appearance of rhinosinusitis. But, this happens also to patients who do not have any irregularities of the nasal septum, that is, they have "straight" nasal septum. Thus, we do not have any realistic record to support the assumption that the deviation of the nasal septum is a dominant factor in the appearance of the above mentioned symptoms. Until today, generally, no method for "screening" the patients candidates for rhinoseptoplasty (RSP) has been accepted. ${ }^{1-3}$

There are several methods to objectively evaluate the rate of nasal obstruction, as rhinomanometry for example, which gives as an objective find on the quality of the performed functional septoplasty after the operation. But the research on the subjective measurements of the nasal symptoms has been limited. In our study we have monitored the patients for a period of one year. We monitored their nasal symptoms using tables and graphs and we tried to show in the simplest way what the benefit of the performed septorhinoplasty was and how it affected the reduction of their symptoms. ${ }^{4-6}$

\section{Materials and methods}

140 patients-candidates for septorhinoplasty were admitted and operated at the University Clinic for Ear, Nose and Throat, University Campus "St. Mother Theresa" in Skopje in the period 2009-2016. Their nasal symptoms which appeared because of the deviation of nasal septum or possible changes in the nasal mucosa were observed. Before the operation, the nasal symptoms in all the patients-candidates for rhinoseptoplasty were observed: nasal obstruction, rhinorrhea, nasal pain, headache, hyposmia, snoring, nasal speech, epistaxis and other. They were recorded on the scale of nasal symptoms. 
The first evaluation was done 3 months after the operation when the operation field was fully recovered. Then, the nasal symptoms were evaluated 6months and 1year after the operation. Before the operation, the nasal symptoms were evaluated in all 140 patients. But in the remaining period, we monitored a total of 110 patients because we had difficulty in monitoring the symptoms in 30 pacients due to the fact that they lacked consistency in regular check-ups. They thought that they didn't have symptoms any more or weren't available for long-term monitoring because of various reasons. Therefore, we didn't take their results into consideration.

\section{Results}

In this part of the research we have presented the results obtained by analyzing patient's nasal symptoms before the operation and one year after the operation, that is, 3, 6 and 12 months after the operation.

\section{Distribution of the frequency of the accompanying nasal symptoms in patients-candidates for septorhinoplasty before and after the operation}

The distribution presented that before the operation all the respondents had nasal obstruction, 3.6\% complained of headache, $50 \%$ had rhinorrhea, while nose bleeding was registered in the smallest number or lowest percentage of respondents - 27 or (19.3\%). After the performed septorhinoplasty, at 3, 6 and 12 month check-ups, reduction was registered in all the analyzed nasal symptoms. The highest reduction in percentages was registered in the nasal obstruction, present in all the patients before the operation. Statistically significant difference in the type of nasal symptoms was confirmed before the operation and 3 months after the operation, while the difference at 6 and 12 months after the operation was statistically insignificant (Table $1 \&$ Graphic 1).

Table I Accompanying nasal symptoms in patients-candidates for septorhinoplasty before and after operation

\begin{tabular}{|c|c|c|c|c|c|}
\hline $\begin{array}{l}\text { Subjective } \\
\text { Symptoms }\end{array}$ & $\begin{array}{l}\text { Before } \\
\text { Operation }\end{array}$ & $\begin{array}{l}3 \text { Months Afteroperation } \\
(\mathrm{N}=\mid \mathrm{I} 0)\end{array}$ & $\begin{array}{l}6 \text { Months } \\
\text { Afteroperation }\end{array}$ & $\begin{array}{l}\text { I Year After } \\
\text { Operation }(\mathrm{N}=|| \mathrm{0})\end{array}$ & $\begin{array}{l}\text { Reduction } \\
\text { In \% }\end{array}$ \\
\hline & $(N=\mid 40)$ & & $(N=|| 0)$ & & \\
\hline Nasal Obstruction & 140 (I00\%) & $27(19.28 \%)$ & $12(8.57 \%)$ & $6(4.28 \%)$ & $95.72 \%$ \\
\hline Rhinorrhea & $70(50 \%)$ & $36(25.71 \%)$ & $12(8.57 \%)$ & $6(4.28 \%)$ & $45.72 \%$ \\
\hline Nasal Pain & $54(38,57 \%)$ & $20(14.28 \%)$ & $5(3.57 \%)$ & $2(1.43 \%)$ & $37.14 \%$ \\
\hline Headache & $89(63.57 \%)$ & $36(25.71 \%)$ & $7(5 \%)$ & $5(3.57 \%)$ & $60 \%$ \\
\hline Hyposmia & $43(30.71 \%)$ & $14(10 \%)$ & $6(4.28 \%)$ & $5(3.57 \%)$ & $27.14 \%$ \\
\hline Snoring & $35(25 \%)$ & $10(7.14 \%)$ & $4(2.86 \%)$ & $3(2.14 \%)$ & $22.86 \%$ \\
\hline Nasal Speech & $45(32.14 \%)$ & $6(4.28 \%)$ & $3(2.14 \%)$ & $2(1.43 \%)$ & $30.71 \%$ \\
\hline Epistaxis & $27(19.28 \%)$ & $4(2.86 \%)$ & $3(2.14 \%)$ & $3(2.14 \%)$ & $17.14 \%$ \\
\hline Other & $18(\mid 2.86 \%)$ & $8(5.7 \mid \%)$ & $6(4.28 \%)$ & $5(3.57 \%)$ & $9.29 \%$ \\
\hline Chi-Square Test & $\mathrm{P}=0,000000$ & $p=0,00000$ & $p=0,08$ & $p=0,75$ & \\
\hline
\end{tabular}

Table 2 Accompanying feeling of difficulty in breathing according to the rate of nasal obstruction

\begin{tabular}{lllll}
\hline Nasal Obstruction & Before Operation & After 3 Months N=I I O & After I 2 Months & Reduction In \% \\
\hline \multirow{2}{*}{ Low } & $\mathrm{N}=140$ & & $\mathrm{n}=\mathrm{I}$ I0 & \\
Moderate & $40(28.57 \%)$ & $8(7.27 \%)$ & $2(1.82 \%)$ & 26.75 \\
Severe & $56(40 \%)$ & $10(9.09 \%)$ & $3(2.73 \%)$ & 37.27 \\
\hline
\end{tabular}

Table 3a Distribution of nasal symptoms in patients-candidates for RSP according to the rate of severity of nasal symptomatology

\begin{tabular}{|c|c|c|c|c|}
\hline $\begin{array}{l}\text { Subjective } \\
\text { Symptoms }\end{array}$ & $\begin{array}{l}\text { No } \\
\text { Symptoms-0 }\end{array}$ & $\begin{array}{l}\text { Low Intensity, } \\
\text { Symptoms } \\
\text { that don't } \\
\text { Interfere - I }\end{array}$ & $\begin{array}{l}\text { Moderate Severe (to } \\
\text { Some Extent Interfere } \\
\text { with everyday activityl } \\
\text { Sleep-2 }\end{array}$ & $\begin{array}{l}\text { Severe ( Severely } \\
\text { Interfere with } \\
\text { Everyday Activities I } \\
\text { Sleep-3 }\end{array}$ \\
\hline Rhinorrhea & $70(50 \%)$ & $56(40 \%)$ & $8(5.71 \%)$ & $6(4.29 \%))$ \\
\hline Nasal pain & $86(61.43 \%)$ & $40(28.57 \%)$ & $9(6.43 \%)$ & $5(3.57 \%)$ \\
\hline Headache & $5 I(36.43 \%)$ & $67(47.86 \%)$ & I4(I9\%) & $8(5.71 \%)$ \\
\hline Hyposmia & $97(69.28 \%)$ & $32(22.86 \%)$ & $6(4.28 \%)$ & $3(2.14 \%)$ \\
\hline Snoring & $105(75 \%)$ & $25(17.86 \%)$ & $6(4.28 \%)$ & $4(2.86 \%)$ \\
\hline Nasal speech & $95(67.86 \%)$ & $36(25.71 \%)$ & $8(5.71 \%)$ & $\mathrm{I}(0.7 \mathrm{I} \%)$ \\
\hline Epistaxis & I I3(80.7I\%) & $21(15 \%)$ & $5(3.57 \%)$ & $\mathrm{I}(0.7 \mathrm{I} \%)$ \\
\hline Other & |22(87.|4\%) & I2(8.57\%) & $5(3.57 \%)$ & $\mathrm{I}(0.7 \mid \%)$ \\
\hline
\end{tabular}

No symptoms - 0

Low intensity - symptoms that do not interfere with everyday activities/sleep-I

Moderate severe- symptoms that to some extent interfere with everyday activities / sleep-2

Severe- symptoms that severely interfere with everyday activities / sleep-3 
Distribution of accompanying feeling of difficulty in breathing as a dominant symptom in nasal obstruction according to the difficulty of nasal obstruction

The results from the research showed that both before the operation and after 3,6 and 12months check-ups after the operation, the lowest was the percentage of patients who felt a mild nasal obstruction that didn't hinder their everyday activities and sleep. In the evaluation of this symptom before the operation and one year after the operation, the reduction in all three intensities was registered, with the highest reduction of the nasal obstruction of moderate intensity, in $37.3 \%$ of patients (Table 2 \& Graphic 2).

\section{Distribution of accompanying nasal symptoms} in patients-candidates for Rhinoseptoplasty (RSP) according to the rate of severity of nasal symptomatology.

Before the operation, the respondents stated as the most frequent nasal symptoms the headache, registered by $89(63.6 \%)$ respondents and rhinorrhea, registered in the questionnaire by $70(50 \%)$ respondents, while the least frequent symptoms were nose bleeding, registered by $27(19.3 \%)$ respondents and snoring while sleeping registered by $35(25 \%)$ respondents. With regard to the severity of these symptoms, all the respondents had low intensity symptoms that didn't hinder their everyday activities and sleep, which is statistically confirmed as highly significant $(\mathrm{p}<0,01)$ (Table 3 \& Graphic 3 ).

\section{Analysis of low intensity nasal symptoms before} operation and 3, 6 and 12 months after operation

Before the opertion, the nasal symptoms were evaluated in all 140 patients. But in the remaining period, we monitored a total of 110 patients because we had difficulty in monitoring the symptoms in 30 pacients due to the fact that they lacked consistency in regular check-ups. They thought that they didn't have symptoms any more or weren't available for long-term monitoring because of various reasons. Therefore, we didn't take their results into consideration. The distribution of the analyzed low intensity nasal symptoms is presented in Table 4 and Graphic 4 for the entire analyzed time period, that is, before operation, and 3, 6 and 12 months after the operation. As we can see from the presented distribution, one year after the operation, the highest reduction in the frequency of the low intensity symptoms was registered in headache. More than half of the respondents suffered from headaches before the operation or $54.5 \%$, while after one year that percentage dropped to $9.1 \%$ respondents. There is a significant reduction in the rhinorrhea, with registered reduction of $38.2 \%$. Before the operation, $16.4 \%$ respondents had low intensity nose bleeding, and one year after the operation it was still present in $4.5 \%$ of the respondents (Table 4, Graphic 4a \& 4b).

Distribution of frequency of moderate nasal symptoms before operation and 3, 6 and 12months after operation

The highest percentage of respondents $12(10.9 \%)$ stated the headache as the symptom with moderate intensity and the nasal pain was present in $7(6.4 \%)$ of the respondents. During a period of monitoring of one year there was a significant reduction in all the analyzed symptoms with moderate intensity, or the symptoms that to some extent interfered with the respondents' everyday activity and sleep. The highest reduction in percentages was registered in headache with $8.2 \%$ of the patients. We can see from the presented distribution that no respondent with hyposmia, nasal speech and nose bleed was registered at the check-up one year after the operation (Table 5, Graphic 5a \& 5b).

\section{Distribution of frequency of severe nasal symptoms before operation and 3,6 and I 2months after operation}

Before the operation the lowest percentage of respondents stated that the nasal symptoms severely interfered with their everyday functioning and sleep. 6 respondents or $5.45 \%$ suffered from headache with severe intensity and rhinorrhea was present in 4 respondents or $3.6 \%$. Six months after the operation, there were no patients registered suffering from snoring, nasal speech or severe epistaxis. One year after the operation there were no patients registered suffering from severe headaches (Table 6, Graphic 6a \& 6b).

Table 3b Significance of the tested differences in the frequency of the nasal symptoms in patients- candidates for RSP before operation

\begin{tabular}{ll}
\hline Subjective Symptoms & Tested Differences Low $/$ Moderate/Severe \\
\hline Rhinorrhea & Pearson Chi-square $=68,69 \mathrm{df}=2 \mathrm{p}=0,000000$ \\
\hline Nasal Pain & Pearson Chi-square $=40,78 \mathrm{df}=2 \mathrm{p}=0,000000$ \\
\hline Headache & Pearson Chi-square $=71,07 \mathrm{df}=2 \mathrm{p}=0,000000$ \\
\hline Hyposmia & Pearson Chi-square $=40,38 \mathrm{df}=2 \mathrm{p}=0,000000$ \\
\hline Snoring & Pearson Chi-square $=23,02 \mathrm{df}=2 \mathrm{p}=0,0000 \mathrm{I}$ \\
\hline Nasal Speech & Pearson Chi-square $=45,73 \mathrm{df}=2 \mathrm{p}=0,000000$ \\
\hline Epistaxis & Pearson Chi-square $=24,89 \mathrm{df}=2 \mathrm{p}=0,000004$ \\
\hline Other & Pearson Chi-square $=10,33 \mathrm{df}=2 \mathrm{p}=0,006$ \\
\hline
\end{tabular}

Table 4 Distribution of frequency of low intensity nasal symptoms before operation and 3,6 and 12 months after operation

\begin{tabular}{llllll}
\hline Low Intensity Symptoms - I & & & & \\
\hline Subjective Symptoms & Before Operation & After 3 Months & After 6 Months & After I Year & Reduction In \% \\
\hline Rhinorrhea & $50(45.45 \%)$ & $36(32.73 \%)$ & $20(18.18 \%)$ & $8(7.27 \%)$ & 38.18 \\
Nasal pain & $35(31.82 \%)$ & $24(21.82 \%)$ & $12(10.91 \%)$ & $6(5.45 \%)$ & 26.37 \\
Headache & $60(54.54 \%)$ & $35(31.82 \%)$ & $26(23.64 \%)$ & $10(9.09 \%)$ & 45.45 \\
Hyposmia & $26(23.64 \%)$ & $16(14.54 \%)$ & $10(9.09 \%)$ & $6(5.45 \%)$ & 18.19 \\
Snoring & $20(18.18 \%)$ & $10(9.09 \%)$ & $6(5.45 \%)$ & $4(3.64 \%)$ & 14.54 \\
Nasal speech & $30(27.27 \%)$ & $15(13.64 \%)$ & $10(9.09 \%)$ & $6(5.45 \%)$ & 21.82 \\
Epistaxis & $18(16.36 \%)$ & $10(9.09 \%)$ & $6(5.45 \%)$ & $5(4.54 \%)$ & 11.82 \\
Other & $10(9,09 \%)$ & $6(5.45 \%)$ & $5(4.54 \%)$ & $4(3.64 \%)$ & 5.45 \\
\hline
\end{tabular}


Table 5 Distribution of frequency of moderate nasal symptoms before operation and 3,6 and 12 months after operation

\begin{tabular}{llllll}
\hline Moderate Symptoms - 2 & & & & & \\
\hline Subjective Symptoms & Before Operation & After 3 Months & After 6 Months & After I Year & Reduction In \% \\
\hline Rhinorrhea & $6(5.45 \%)$ & $4(3.64 \%)$ & $3(2.73 \%)$ & $\mathrm{I}(0.91 \%)$ & 4.54 \\
Nasal pain & $7(6.36 \%)$ & $5(4.54 \%)$ & $2(1.82 \%)$ & $\mathrm{I}(0.91 \%)$ & 5.45 \\
Headache & $12(10.91 \%)$ & $8(7.27 \%)$ & $6(5.45 \%)$ & $3(2.73 \%)$ & 8.18 \\
Hyposmia & $4(3.64 \%)$ & $3(2.73 \%)$ & $2(1.82 \%)$ & 0 & 3.64 \\
Snoring & $5(4.54 \%)$ & $3(2.73 \%)$ & $2(1.82 \%)$ & $\mathrm{I}(0.91 \%)$ & 3.63 \\
Nasal speech & $6(5.45 \%)$ & $3(2.73 \%)$ & $\mathrm{I}(0.91 \%)$ & 0 & 5.45 \\
Epistaxis & $4(3.64 \%)$ & $2(1.82 \%)$ & 0 & 0 & 3.64 \\
Other & $3(2.73 \%)$ & $2(1.82 \%)$ & $\mathrm{I}(0.91 \%)$ & $\mathrm{I}(0.91 \%)$ & 1.82 \\
\hline
\end{tabular}

Table 6 Distribution of frequency of severe nasal symptoms before operation and 3,6 and 12 months after operation

\begin{tabular}{llllll}
\hline Severe Symptoms-2 & \multicolumn{1}{l}{} \\
\hline Subjective Symptoms & Before Operation & After 3 Months & After 6 Months & After I Year & Reduction In \% \\
\hline Rhinorrhea & $4(3.64 \%)$ & $3(2.73 \%)$ & $2(I .82 \%)$ & $2(I, 82 \%)$ & $\mathrm{I}, 82$ \\
Nasal pain & $3(2.73 \%)$ & $\mathrm{I}(0.91 \%)$ & $\mathrm{I}(0.91 \%)$ & $\mathrm{I}(0,91 \%)$ & $\mathrm{I}, 82$ \\
Headache & $6(5.45 \%)$ & $4(3.64 \%)$ & $2(1.82 \%)$ & 0 & 5,45 \\
Hyposmia & $2(1.82 \%)$ & $\mathrm{I}(0.91 \%)$ & $\mathrm{I}(0.91 \%)$ & $\mathrm{I}(0,91 \%)$ & 0,92 \\
Snoring & $2(1.82 \%)$ & $\mathrm{I}(0.91 \%)$ & 0 & 0 & $\mathrm{I}, 82$ \\
Nasal speech & $\mathrm{I}(0.91 \%)$ & 0 & 0 & 0 & $0,9 \mid$ \\
Epistaxis & $\mathrm{I}(0.91 \%)$ & 0 & 0 & 0 & $0,9 \mid$ \\
Other & $\mathrm{I}(0.91 \%)$ & $\mathrm{I}(0.91 \%)$ & $\mathrm{I}(0.91 \%)$ & $\mathrm{I}(0.91 \%)$ & 0 \\
\hline
\end{tabular}

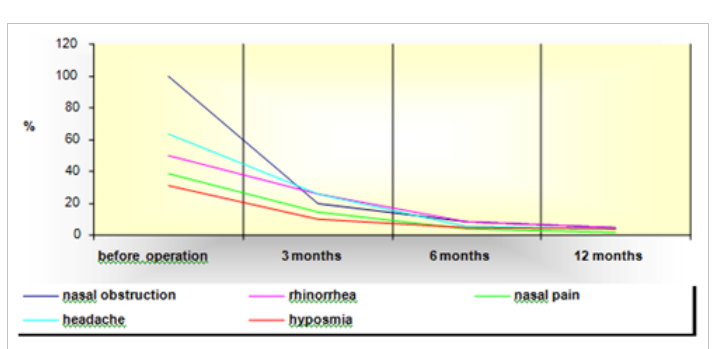

Graphic Ia Distribution of the frequency of accompanying nasal symptoms in patents-candidates for septorhinoplasty before and after operation.

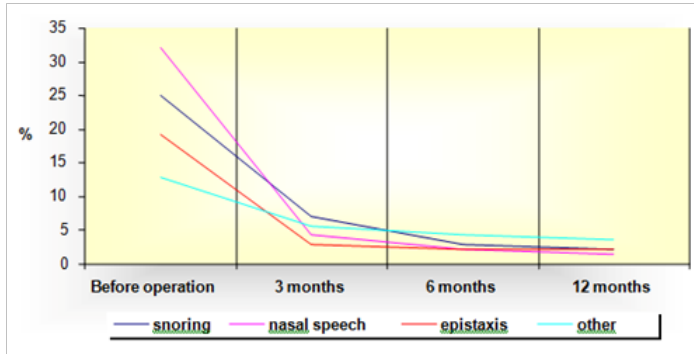

Graphic Ib Distribution of the additional nasal symptoms in patentscandidates for septorhinoplasty before and after operation.

\section{Discussion}

Logically it can be expected that most of the respondents have asymmetrical nasal flow through both nostrils which is associated with the deviation of the nasal septum. If the deviation of the nasal septum is bigger and the nasal resistance is more severe, the nasal symptoms would dominate which would lead to one way or two way hypertrophy of the nasal concha. That indicates that when selecting the patients-candidates for rhinoseptoplasty around $20 \%$ of them would have relatively symmetric nasal flow. The difficulties in determining the effects of the nasal septal deviation on the nasal function and air flow through the nose is in correlation with the difficulties in determining the role of the nasal septal deviation on the function of the nasal valve. ${ }^{7-9}$

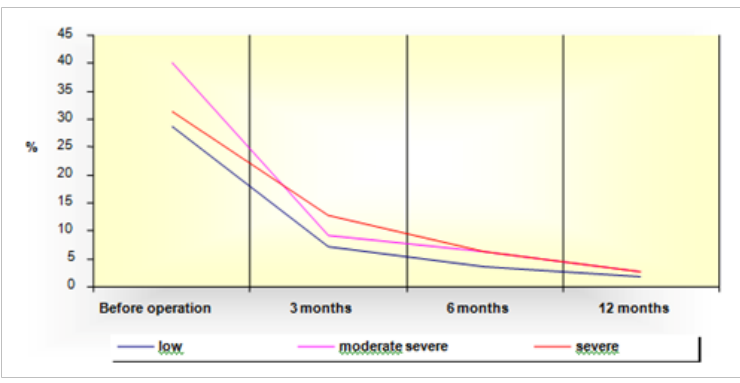

Graphic 2 Distribution of the feeling of difficulty in breathing according to the rate of nasal obstruction.

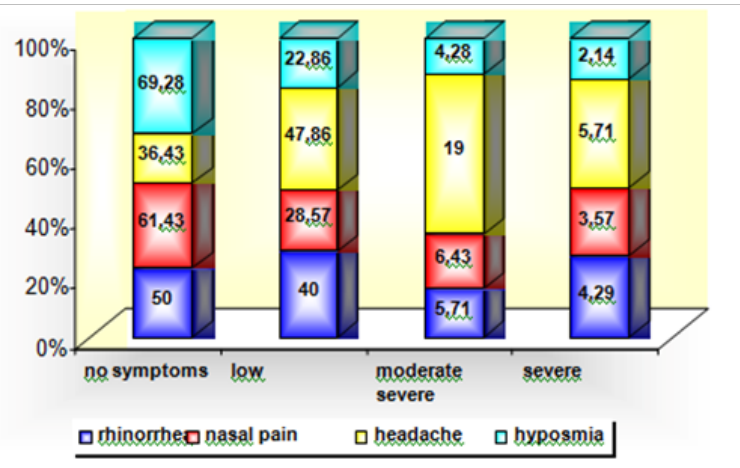

Graphic 3a Distribution of nasal symptoms in patients-candidates for RSP according to the rate of severity of nasal symptomatology.

The minor deviations of the nasal septum which are in the area of the nasal valves have bigger influence on the appearance and strength of the nasal symptoms than the other types of deviations. Therefore, as we have previously shown, the objective measurements are the most exact when selecting patients for septal surgery and their monitoring after the operation. 


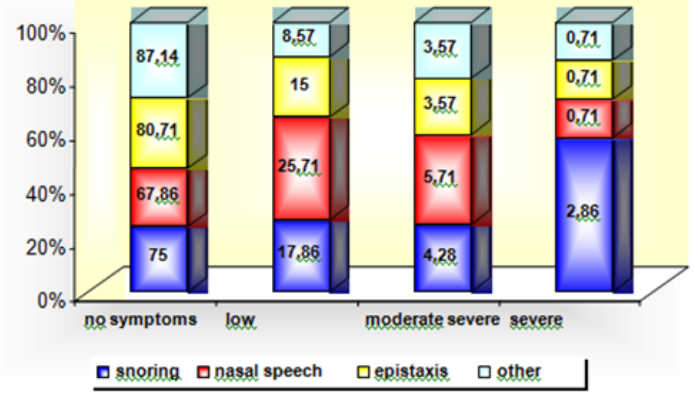

Graphic 3b Distribution of nasal symptoms in patients-candidates for RSP according to the rate of severity of nasal symptomatology.

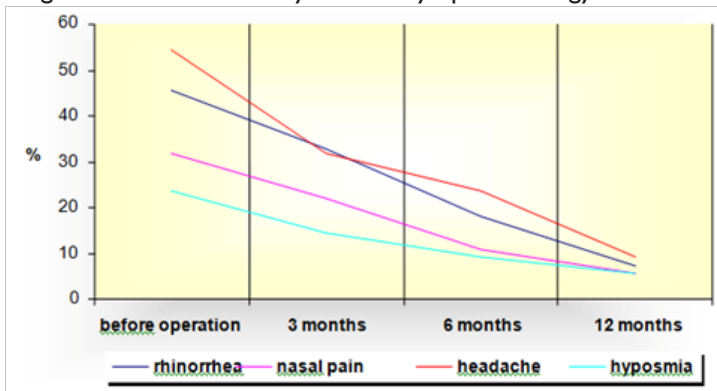

Graphic 4a Distribution of frequency of low intensity nasal symptoms before operation and 3,6 and 12 months after operation.

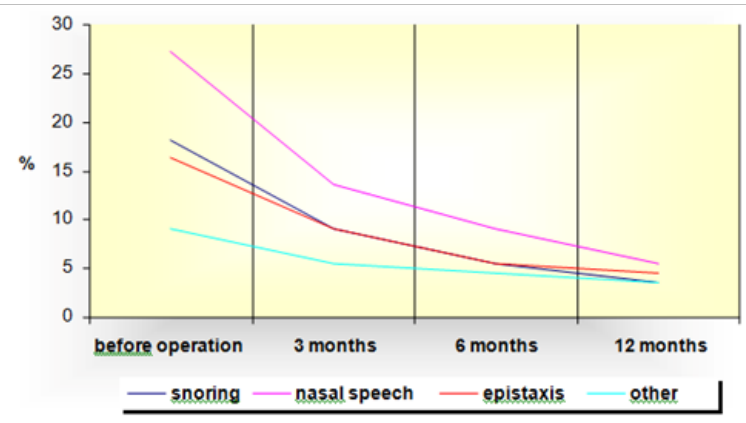

Graphic 4b Distribution of frequency of low intensity nasal symptoms before operation and 3,6 and 12 months after operation.

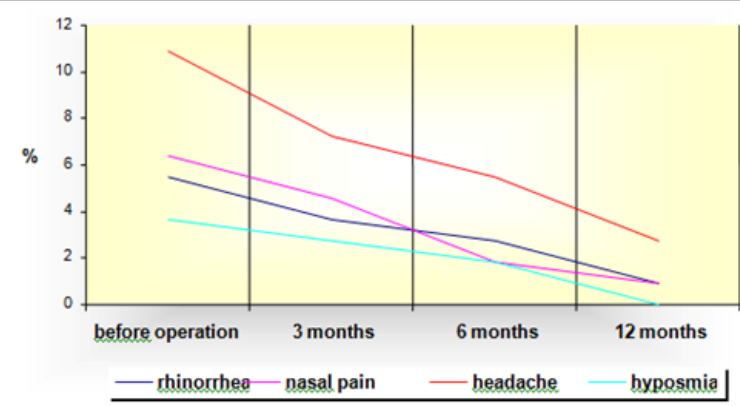

Graphic 5a Distribution of frequency of moderate nasal symptoms before operation and 3,6 and 12 months after operation.

The patients-candidates for rhinoseptoplasty experience difficulty in breathing as a dominant nasal obstruction symptom. ${ }^{10,11}$

The results from the research have shown that before the operation and at 3,6 and 12month check-up, the lowest was the percentage of respondents who felt the nasal obstruction as mild and it didn't interfere with their everyday activities and sleep. It is almost a constant and it is dominant in all the rates of nasal obstruction, but because it is of a "bony" type, that is, because of the deviation of certain segments of the nasal septum (cartilaginous or bony) it shows drastic reduction after the operation. In the evaluation of this symptom before the operation and one year after the operation reduction in all three intensities was registered. The highest percentage of nasal obstruction reduction was with moderate intensity in $37.3 \%$ of the respondents.

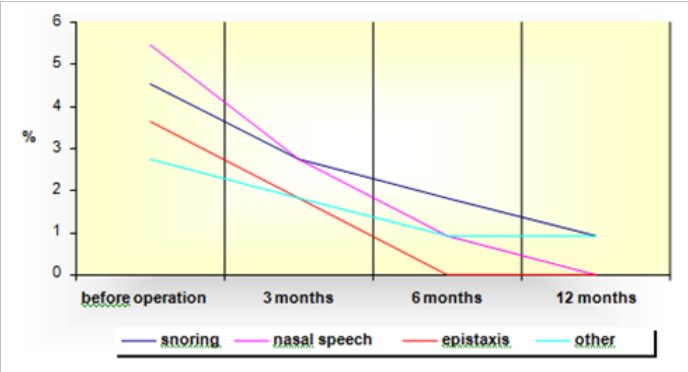

Graphic $\mathbf{5 b}$ Distribution of frequency of moderate nasal symptoms before operation and 3,6 and 12 months after operation.

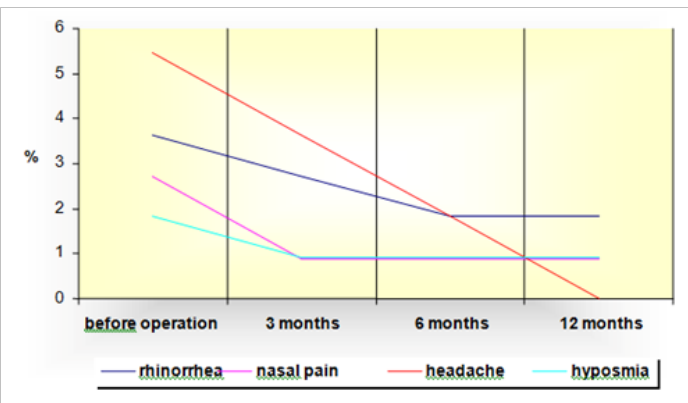

Graphic 6a Distribution of frequency of severe nasal symptoms before operation and 3,6 and 12 months after operation.

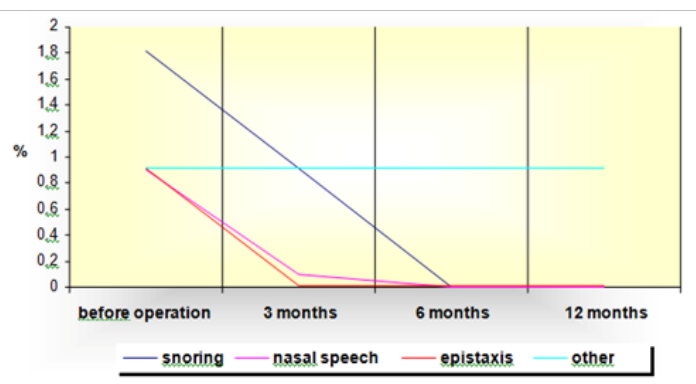

Graphic 6b Distribution of frequency of severe nasal symptoms before operation and 3,6 and 12 months after operation.

In the cases where the nasal obstruction is of "mucosal" type, that is, if there are changes in the nasal mucosa (hypertrophy of the nasal mucosa, nasal concha or accompanying inflammation) there is a graduate reduction in the nasal obstruction after the operation and it should be additionally treated with medicamentous therapy after the operation (most commonly with nasal topical corticosteroids). ${ }^{12,13}$

As the most frequent nasal symptom before the operation, the respondents state the headache $-63.6 \%$ respondents and rhinorrhea $50 \%$ respondents. The least frequent symptoms are nose bleeding and snoring while sleeping. Regarding the severity of these symptoms, low intensity symptoms are dominant, that is, symptoms that do not interfere with the respondents' everyday activities and sleep, which was statistically proved as highly significant $(\mathrm{p}<0,01)$. The dominant 
symptom in patients with nasal septal deviation is the headache and it is consistent in the period after the operation. That can be a sign that it appears in patients also because of certain subjective reasons, which are most often the result of psychogenic nature: anxiety, agitation and very high expectations from the operation.

Rhinorrhea is drastically reduced because with the correction of the nasal septum, the edema and hypertrophy of the nasal mucosa are alleviated, especially the changes in the nasal conchae, so it leads to reduction in exudation of the nasal fluid. The appearance of epistaxis is detected in nasal septal deviations in the front and front-back parts more, but with no significance. That would lead us to think that other functional, inflammatory, subjective and other causes can lead to appearance of these symptoms. The nasal septal deviation affects the respiratory cycle and normal breathing. ${ }^{14}$

The American Academy of Otolaryngology - Head and Neck Surgery, has produced a prospective study on the septoplasty effect, with or without mucotomia in a follow-up period of 6months. However, longitudinal studies on the effectiveness of septoplasty, especially in reducing the nasal symptoms, specifically the nasal obstruction in a long period of time are very rare. ${ }^{8}$

Previous studies show various results with regard to the connection between subjective and objective nasal evaluations and show weak connection between them, unlike the comparative studies implemented with objective evaluations measured with rhinomanometry, acoustic rhinometry and the subjective measurements implemented with VAS (Visual Analogue Scale). ${ }^{15,16}$

In this study we have evaluated the results before and after the operation in several follow-up periods. This information is useful both for the surgeon and the patient because it provides realistic expectations on the benefit of the operation. By developing the scale on the intensity of the nasal symptoms we wanted to help the surgeon in his or her expectations in the period after the operation. Thus, besides the accurate assumption and monitoring before the operation, attention should be paid to the intensity after the operation and accordingly use additional treatment if necessary.

The results of our clinical research show relative connection between the anatomical, psychological and subjective categories which interfere in the evaluation of the nasal symptoms.

The results significantly show the correlation between the anatomic (objective) and psychological (subjective) reasons that determine the frequency and severity of the present nasal symptoms.

The results show the connection between the anatomy of the nasal passage and pathophysiology of the nasal flow in the nasal septal deviation as immediate causes for the appearance of nasal symptomatology. Therefore, this complicates the research and it is difficult to simplify it as just one comparative analysis.

For example, the nasal flow and the pathophysiology of the nasal flow and the appearance of the nasal symptoms, do not represent a completely static element, thus the static find in the rhinomanometry evaluations could not reflect the dynamic changes in the nasal resistance and the nasal flow which is in correlation with its turbulence.

The extensive study on the measurements of objective and subjective nasal symptoms produced in America in 2005 implies another important detail which creates certain limitations to these evaluations: seasonal variations affect the nasal flow and the appearance of nasal symptoms, respiratory comorbidity and allergies as well. They have not been included in almost all the evaluations done so far and they make the relevancy of the research difficult. Anyway, significant respiratory pathological conditions and abnormalities were not frequent in our research. ${ }^{17,18}$

\section{Conclusion}

Our clinical research presented differences in the results obtained from the patients, that is, their interpretation of the nasal symptoms in relation to the results obtained from objective rhinomanometry measurements, as well as the anatomic abnormalities of the nasal septum obtained from the performed $\mathrm{CT}$ on the nose and the paranasal sinuses and the objective intraoperative findings. The results showed that besides the septal deviation, certain factors can cause reduced resistance in the nasal passages: nasal hypersecretion, nasal concha hyperplasia, isthmus stenosis, inspiratory nasal valve collapse or other factors that lead to pathological nasal turbulence. We must not forget the psychological factor at any time.

Therefore, without appropriate postoperative nasal functional diagnostics, rhinoseptoplasty will not always be successful. ${ }^{19-21}$

\section{Acknowledgments}

None.

\section{Conflicts of interest}

Author declares there are no conflicts of interest.

\section{Funding}

None.

\section{References}

1. Hilberg O, Jackson AC, Swift DL, et al. Acoustic rhinometry: Evaluation of nasal cavity geometry by acoustic reflection. J Appl Physiol. 1985;66:295-303.

2. Dunagan D, Georgitis J. Intranasal disease and provocation. Clin Allergy Immunol. 2000;15:151-73.

3. Kemp S, Lockey R. Marcel Dekker, New York, USA. 2000. p. 151-173.

4. Hilberg O, Jensen FT, Pedersen OF. Nasal airway geometry: Comparison between acoustic reflections and magnetic resonance scanning. $J$ Appl Physiol . 1993;75(6):2811-2819.

5. Corey JP, Gungor A, Nelson R, et al. A comparison of the nasal cross-sectional areas and volumes obtained with acoustic rhinometry and magnetic resonance imaging. Otolaryngol Head Neck Surg. 1997;117(4):349-354.

6. Corey JP, Nalbone VP, Ng BA. Anatomic correlates of acoustic rhinometry as measured by rigid nasal endoscopy. Otolaryngol Head Neck Surg. 1999;121(5):572-576.

7. Holmström M, Scadding GK, Lund VJ, et al. Assessment of nasal obstruction. A comparison between rhinomanometry and nasal inspiratory peak flow. Rhinology. 1990;28(3):191-196.

8. Jones AS, Viani L, Phillips D, et al. The objective assessment of nasal patency. Clin Otolaryngol. 1991;16(2):206-211.

9. Wihl JA, Malm L. Rhinomanometry and nasal peak expiratory and inspiratory flow rate. Ann Allergy. 1998;61(1):50-55.

10. Min YG, Jan YJ. Measurements of cross-sectional area of the nasal cavity by acoustic rhinometry and CT scanning. Laryngoscope. 1995;105(7 Pt 1):757-759.

11. Mamikoglu B, Houser S, Akbar I, et al. Acoustic rhinometry and computed tomography scans for the diagnosis of nasal septal deviation, with clinical correlation. Otolaryngol Head Neck Surg. 2000;123(1 Pt 1): 61-68. 
12. Terheyden H, Maune S, Mertens J, et al. Acoustic rhinometry: Validation by three-dimensionally reconstructed computer tomographic scans. $J$ Appl Physiol. 2000;89(3):1013-1021.

13. Stewart MG, Witsell DL, Smith TL, et al. Development and validation of the nasal obstruction symptom evaluation (NOSE) scale. Otolaryngol Head Neck Surg. 2004;130(2):157-163.

14. Ciprandi G, Klersy C, Ameli F, et al. Clinical assessment of a nasal decongestion test by visual analog scale in allergic rhinitis. Am J Rhinol. 2008;22(5):502- 505 .

15. Schumacher MJ. Nasal dyspnea: the place of rhinomanometry in its objective assessment. Am J Rhinol. 2004;18(1):41-46.

16. Nathan RA, Eccles R, Howarth PH, et al. Objective monitoring of nasal patency and nasal physiology in rhinitis. J Allergy Clin Immunol. 2005;115(3 Suppl 1):S442-S459.

17. Rhee JS, Arganbright JM, McMullin BT, et al. Evidence supporting functional rhinoplasty or nasal valve repair: A 25-year systematic review. Otolaryngol Head Neck Surg . 2008;139(1):10-20.
18. DeVine J, Norvell DC, Ecker E, et al. Evaluating the correlation and responsiveness of patient-reported pain with function and quality-oflife outcomes after spine surgery. Spine (Phila Pa 1976). 2011; 36(21 Suppl):S69-S74.

19. Beekhuis GJ. Nasal obstruction after rhinoplasty: etiology, and techniques for correction. Laryngoscope. 1976;86(4):540-548.

20. Haye R, Tarangen M, Shiryaeva O, et al. Evaluation of the Nasal Surgical Questionnaire for Monitoring Results of Septoplasty. Int J Otolaryngol. 2015;2015(2015):7.

21. Rhee JS, Sullivan CD, Frank DO, et al. A systematic review of patientreported nasal obstruction scores: defining normative and symptomatic ranges in surgical patients. JAMA Facial Plast Surg. 2014;16(3):219-225. 